\title{
Contamination with retinoic acid receptor agonists in two rivers in the Kinki region of Japan
}

\author{
Daisuke Inoue ${ }^{a}, K_{\text {Koki Nakama }}^{a}$, Kazuko Sawada ${ }^{a}$, Taro Watanabe ${ }^{a}$, Mai Takagi ${ }^{a}$, \\ Kazunari Sei ${ }^{a}$, Min Yang ${ }^{b}$, Junji Hirotsuji ${ }^{c}$, Jianying $\mathrm{Hu}^{d}$, Jun-ichi Nishikawa ${ }^{e}$, \\ Tsuyoshi Nakanishi ${ }^{f}$, Michihiko Ike ${ }^{a, *}$ \\ a Division of Sustainable Energy and Environmental Engineering, Osaka University, 2-1 Yamadaoka, Suita, Osaka 565-0871, Japan \\ ${ }^{\mathrm{b}}$ State Key Laboratory of Environmental Aquatic Chemistry, Research Center for Eco-Environmental Sciences, \\ Chinese Academy of Sciences, Beijing 100085, China \\ c Advanced Technology R\&D Center, Mitsubishi Electric Co., 8-1-1 Tsukaguchi-Honmachi, Amagasaki, Hyogo 661-8661, Japan \\ ${ }^{\mathrm{d}}$ College of Urban and Environmental Sciences, Peking University, Beijing 100871, China \\ e Laboratory of Health Sciences, School of Pharmacy and Pharmaceutical Sciences, Mukogawa Women's University, \\ 11-68 Kyuban-cho, Koshien, Nishinomiya, Hyogo 663-8179, Japan \\ ${ }_{\mathrm{f}}^{\mathrm{L}}$ Laboratory of Hygienic Chemistry and Molecular Toxicology, Gifu Pharmaceutical University, 5-6-1 Mitahora-higashi, \\ Gifu, Gifu 502-8585, Japan
}

\section{A R T I C L E I N F O}

\section{Article history:}

Received 18 September 2009

Received in revised form

25 December 2009

Accepted 5 January 2010

Available online 14 January 2010

Keywords:

Retinoic acid receptor (RAR)

RAR $\alpha$ agonistic activity

River

Surface water

Yeast two-hybrid assay

\begin{abstract}
A B S T R A C T
This study was conducted to investigate the agonistic activity against human retinoic acid receptor (RAR) $\alpha$ in the Lake Biwa-Yodo River and the Ina River in the Kinki region of Japan. To accomplish this, a yeast two-hybrid assay was used to elucidate the spatial and temporal variations and potential sources of RAR $\alpha$ agonist contamination in the river basins. RAR $\alpha$ agonistic activity was commonly detected in the surface water samples collected along two rivers at different periods, with maximum all-trans retinoic acid (atRA) equivalents of $47.6 \mathrm{ng}$-atRA/L and $23.5 \mathrm{ng}$-atRA/L being observed in Lake Biwa-Yodo River and Ina River, respectively. The results indicated that RAR $\alpha$ agonists are always present and widespread in the rivers. Comparative investigation of RAR $\alpha$ and estrogen receptor $\alpha$ agonistic activities at 20 stations along each river revealed that the spatial variation pattern of RAR $\alpha$ agonist contamination was entirely different from that of the estrogenic compound contamination. This suggests that the effluent from municipal wastewater treatment plants, a primary source of estrogenic compounds, seemed not to be the cause of RAR $\alpha$ agonist contamination in the rivers. Fractionation using high performance liquid chromatography (HPLC) directed by the bioassay found two bioactive fractions from river water samples, suggesting the presence of at least two RAR $\alpha$ agonists in the rivers. Although a trial conducted to identify RAR $\alpha$ agonists in the major bioactive fraction was not completed as part of this study, comparison of retention times in HPLC analysis and quantification with liquid chromatography-mass spectrometry analysis revealed that the major causative contaminants responsible for the RAR $\alpha$ agonistic activity were not RAs (natural RAR ligands) and 4-oxoRAs, while 4-oxo-RAs were identified as the major RAR agonists in sewage in Beijing, China. These findings suggest that there are unknown RAR $\alpha$ agonists with high activity in the rivers.

(c) 2010 Elsevier Ltd. All rights reserved.
\end{abstract}

\footnotetext{
* Corresponding author. Tel.: +81 66879 7672; fax: +81 668797675 .

E-mail address: ike@see.eng.osaka-u.ac.jp (M. Ike).
} 


\section{Introduction}

There has been great concern regarding environmental contaminants that disrupt or alter functions of the endocrine system primarily by binding to nuclear receptors and subsequently causing detrimental effects in intact organisms. The occurrence and fate of these so-called endocrine disrupting chemicals in the aquatic environment have been extensively studied while mainly focusing on compounds that interfere with steroid hormone receptors such as estrogen receptor (ER) and androgen receptor (Campbell et al., 2006; Sharma et al., 2009). However, it has been shown that the nuclear receptor superfamily contains many different receptors in eukaryotic organisms (Chawla et al., 2001), and each member of the nuclear receptor superfamily can mediate endocrine disruptive effects (Janošek et al., 2006; Tabb and Blumberg, 2006).

Retinoic acid (RA) receptors (RARs) are members of the nuclear receptor superfamily whose specific natural ligands are all-trans RA (atRA) and 9-cis RA (9cRA) derived from retinoid (vitamin A) precursors (Chambon, 1996). RAs are essential for hematopoiesis, immune function, vision, reproduction and embryonic patterning, as well as growth and differentiation in vertebrates (Sporn et al., 1994; Kastner et al., 1995; Chambon, 1996). However, both deficiency and excess of RAs and related retinoids during pregnancy cause abnormal morphological development (teratogenesis) of various organs and tissues, such as the eye, brain, heart, segment and limbs in the offspring (Collins and Mao, 1999; Zile, 2001). Teratogenesis by excess RAs has been observed in various vertebrates including fish (Herrmann, 1995; Haga et al., 2002), amphibians (Degitz et al., 2000, 2003; Alsop et al., 2004) and mammals (Lee et al., 1995; Ritchie et al., 2003). It has also been reported that high dietary intake of vitamin A by pregnant women can cause birth defects (Rothman et al., 1995). Based on the available evidence, it is clear that the environmental occurrence of RA mimics that disrupt RAR signaling may cause detrimental effects in animals and humans.

Gardiner et al. (2003) first detected RAR agonistic activity in the natural aquatic environment. During an investigation of the cause of the occurrence of deformed frogs in North America, they found that $\mathrm{RAR} \alpha$ agonistic activity was commonly found in water samples from a lake in Minnesota and a pond in California in which frog malformations were routinely found. However, the causative contaminants, which were named environmental retinoids, were not identified (Gardiner et al., 2003). Very recently, RAR agonistic activity was detected in wastewater treatment plants (WWTPs) and their receiving rivers in Beijing, China (Zhen et al., 2009) and several rivers in the Kinki region of Japan (Inoue et al., 2009). The results of these studies confirmed that RAR agonist contamination exists in the aquatic environment. In addition, the major causative RAR agonists in sewage in Beijing, China were first identified as 4-oxo-atRA and 4-oxo-13-cis RA (4-oxo13cRA), which are oxidative metabolites of RAs, by Zhen et al. (2009). However, there is still very little available information regarding contamination of aquatic environments with RAR agonists. Specifically, to assess the possible risks of RAR agonists in the aquatic environment, it is still necessary to determine how widespread RAR agonist contamination is in the aquatic environment, how such contamination varies temporally and spatially, and whether 4-oxo-RAs are commonly the causative RAR agonists or other causative RAR agonists exist.

In this study, the RAR $\alpha$ agonistic activity was determined in detail in the Lake Biwa-Yodo River and the Ina River in the Kinki region of Japan using a yeast two-hybrid assay to elucidate spatial and temporal variations in RAR $\alpha$ agonist contamination and potential sources of RAR $\alpha$ agonists in the rivers. In addition, bioassay-directed high performance liquid chromatography (HPLC) fractionation was conducted to characterize the causative contaminants.

\section{Materials and methods}

\subsection{Chemicals}

AtRA, 13cRA, 17 $\beta$-estradiol (E2) and methanol (MeOH) were purchased from Sigma-Aldrich (St. Louis, MO, USA). 9cRA, dimethyl sulfoxide (DMSO) and ammonium acetate were purchased from Wako Pure Chemical Industries (Osaka, Japan). Acetonitrile was purchased from Kanto Chemical (Tokyo, Japan). 4-Oxo-RAs (4-oxo-atRA, 4-oxo-9cRA and 4-oxo-13cRA) were purchased from Toronto Research Chemicals (Toronto, Canada). 2-Nitrophenyl- $\beta$-D-galactoside (ONPG) was purchased from Tokyo Chemical Industry (Tokyo, Japan). Zymolyase-20T was purchased from ICN Biomedicals Inc. (Costa Mesa, CA, USA). $\mathrm{MeOH}$ and acetonitrile were high-performance liquid chromatography (HPLC) grade, while the other chemicals were of the highest grade commercially available.

\subsection{Surface water samples}

Grab samples were collected from the subsurface zone (30- to $50-\mathrm{cm}$ depth) at 20 stations along the Lake Biwa-Yodo River and 20 stations along the Ina River in the Kinki region of Japan (Fig. 1). The Lake Biwa-Yodo River is the largest watershed in the Kinki region of Japan, with a catchment area of $8,240 \mathrm{~km}^{2}$. This river is the primary source of drinking water for the more than 14 million residents of Osaka City and its 24 circumjacent cities. The Ina River is a tributary of the Yodo River that runs along the border of Osaka and Hyogo Prefectures, with a catchment area of $383 \mathrm{~km}^{2}$. The Ina River is a high priority river with respect to environmental conservation; however, this river is regarded as a highly polluted one as characterized with high levels of biochemical oxygen demand. Samples were collected at stations 2, 4, 8 and 18 of the Lake Biwa-Yodo River and stations 5, 8, 11, 12, 17 and 18 of the Ina River in June, August and October 2007 and January 2008. Samples were also collected from all 20 stations in the Ina River and Lake BiwaYodo River in April and October 2008, respectively. Additional samples were obtained from station 18 of the Ina River in July 2008 and April and October 2009. The quality of the surface water samples (range (median)) in the Lake Biwa-Yodo River and the Ina River were as follows: $\mathrm{pH}, 6.5-8.8$ (7.2) and 6.4-8.7 (7.3); dissolved organic carbon, $1.3-6.7 \mathrm{mg} / \mathrm{L} \mathrm{(3.2} \mathrm{mg/L)} \mathrm{and}$ 0.37-12 mg/L (3.4 mg/L); total nitrogen, 0.092-5.8 mg/L (2.2 mg/L) and $0.41-14 \mathrm{mg} / \mathrm{L}(1.4 \mathrm{mg} / \mathrm{L})$, respectively (Supplementary 


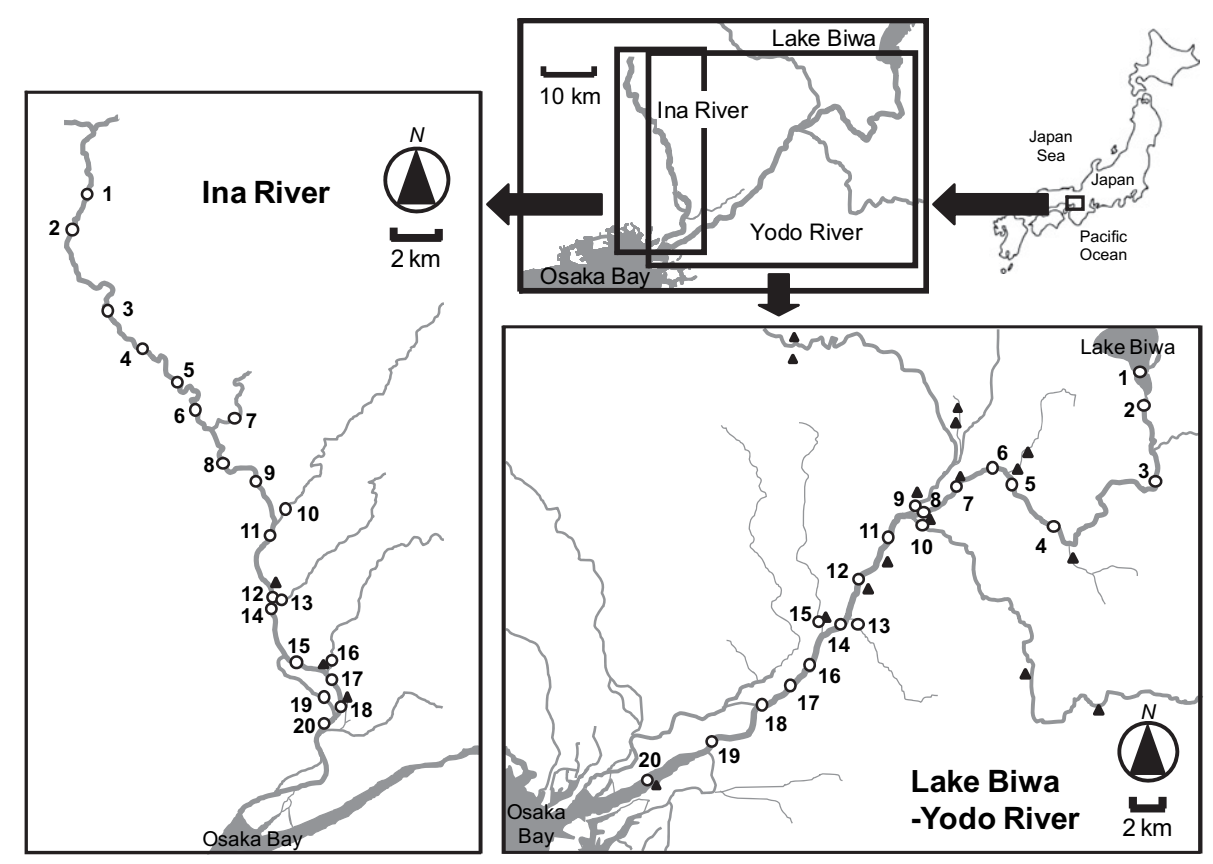

Fig. 1 - Location of sampling stations (open circle) and relevant municipal wastewater treatment plants (closed triangle) in Lake Biwa-Yodo River and Ina River. Sampling stations in each river are numbered from 1 to 20.

Table S1). All samples were transported on ice to the laboratory, and solid phase extraction (SPE) of the samples was conducted within $12 \mathrm{~h}$ of collection.

\subsection{Sample preparation}

Prior to SPE, water samples were filtered using a Whatman GF/B filter (pore size $1.0 \mu \mathrm{m}$, Whatman, Maidstone, Kent, UK) to remove the insoluble materials, and then two liters of the filtered water sample without $\mathrm{pH}$ adjustment were passed through an Oasis HLB cartridge $(6 \mathrm{ml}, 500 \mathrm{mg}$, Waters, Milford, MA, USA) that had previously been conditioned with $6 \mathrm{ml}$ of $\mathrm{MeOH}$ and $6 \mathrm{ml}$ of ultra pure water at a flow rate of $5-10 \mathrm{ml} / \mathrm{min}$. After the cartridge was washed with $6 \mathrm{ml}$ of ultra pure water and dried, the absorbed substances were eluted from the cartridge with $6 \mathrm{ml}$ of $\mathrm{MeOH}$. The extracts were then dried under a gentle nitrogen stream. The dried residue was dissolved in $200 \mu$ l of DMSO (for yeast two-hybrid assay) or $\mathrm{MeOH}$ (for HPLC fractionation), resulting in a concentration factor of 10,000 fold when compared with the original water sample.

\subsection{Yeast two-hybrid assay}

A yeast two-hybrid assay employing the recombinant yeast, Saccharomyces cerevisiae Y190, which contained the human RAR $\alpha$ or ER $\alpha$ and the coactivator TIF2 (Nishikawa et al., 1999), was applied to evaluate the agonistic activity of the samples on $\mathrm{RAR} \alpha$ or $\mathrm{ER} \alpha$, respectively. The assay was conducted as described previously (Inoue et al., 2009). Briefly, aliquots of test samples $(1 \%(\mathrm{v} / \mathrm{v}))$ were incubated $\left(30^{\circ} \mathrm{C}, 4 \mathrm{~h}\right)$ with yeast cells that had been precultured at $30^{\circ} \mathrm{C}$ for $18 \mathrm{~h}$ in SD medium lacking tryptophan and leucine. After measuring the yeast cell density $\left(\mathrm{OD}_{620}\right)$ with a plate reader (Viento XS, Dainippon
Sumitomo Pharma, Osaka, Japan), the yeast cells were digested with zymolyase-20T at $30^{\circ} \mathrm{C}$ for $30 \mathrm{~min}$. Next, ONPG was added as the substrate for $\beta$-galactosidase, and the solution was incubated at $30^{\circ} \mathrm{C}$ for $20 \mathrm{~min}$. After adding $\mathrm{Na}_{2} \mathrm{CO}_{3}$, the absorbance at 414 and $540 \mathrm{~nm}\left(\mathrm{~A}_{414}\right.$ and $\mathrm{A}_{540}$, respectively) was measured and the $\beta$-galactosidase activity was calculated as $1000 \times\left(\mathrm{A}_{414}-1.75 \times \mathrm{A}_{540}\right) / \mathrm{OD}_{620}$. Each experiment included a negative control that consisted of $1 \%$ DMSO without any environmental sample. In addition, various concentrations of atRA and E2 were assayed to produce a standard curve for $\mathrm{RAR} \alpha$ and $\mathrm{ER} \alpha$, respectively. All assays were conducted in triplicate, except for the agonistic activity assays of ER $\alpha$ for a sample from station 12 of the Ina River collected in June 2007 and a sample from station 17 of the Ina River collected in October 2007, which were analyzed in duplicate due to a lack of samples. The relative agonistic activities (\%) of the samples were calculated by setting the maximum $\beta$-galactosidase activity of the positive chemical and $\beta$-galactosidase activity of the negative control at $100 \%$ and $0 \%$, respectively (Inoue et al., 2009). According to the method developed to evaluate the estrogenicity of environmental samples (Kawagoshi et al., 2003), the atRA equivalents (atRA-EQ) of the samples were calculated using the following equation: atRA-EQ (ng/L) $=$ (the atRA concentration $(\mathrm{ng} / \mathrm{L})$ that gave $10 \%$ relative $\mathrm{RAR} \alpha$ agonistic activity)/(the concentration factor of the test sample that gave $10 \%$ relative $\mathrm{RAR} \alpha$ agonistic activity).

\subsection{Reverse-phase HPLC fractionation}

Reverse-phase HPLC fractionation of the samples was performed using a Shimadzu LC-10Avp HPLC system consisting of an SIL-10AF automatic sampler, two LC-10ADup solvent delivery units, a CTO-10Aup column oven and an SPD-10Aup 
UV/VIS detector (Shimadzu, Kyoto, Japan). The instrument was equipped with a Shim-Pack VP-ODS column $(250 \times 4.6 \mathrm{~mm}$ [i.d.]; particle size, $5 \mu \mathrm{m}$; Shimadzu). An aliquot (100 $\mu \mathrm{l})$ of the extract dissolved in $\mathrm{MeOH}$ was injected into the column and eluted over $45 \mathrm{~min}$ at a flow rate of $1.0 \mathrm{ml} / \mathrm{min}$, with UV detection at $254 \mathrm{~nm}$ or $360 \mathrm{~nm}$. Acetonitrile/ultra pure water was used as the mobile phase with the following gradient of acetonitrile: 0 to $3 \mathrm{~min}, 20 \%$; 3 to $30 \mathrm{~min}$, a linear gradient from $20 \%$ to $100 \%$; 30 to $40 \mathrm{~min}, 100 \%$; 40 to $45 \mathrm{~min}, 20 \%$. The discrete fractions were collected at 2- or 0.5 -min intervals, dried and redissolved in DMSO for the yeast two-hybrid assay.

To determine the retention times (RTs) of RAs (natural RAR ligands) and 4-oxo-RAs (RAR agonists identified in sewage in Beijing, China (Zhen et al., 2009)), $100 \mu$ l of each authentic compound (i) dissolved in $\mathrm{MeOH}$ and (ii) spiked into the extract of surface water sample dissolved in $\mathrm{MeOH}$ were injected and analyzed as described above. After analysis of these standards, $\mathrm{MeOH}$ was injected several times to avoid contamination of the HPLC system.

\subsection{LC mass spectrometry (LC/MS)}

The bioactive HPLC fraction were analyzed using a Shimadzu LCMS-2010EV system consisting of a Shimadzu LC-20A HPLC system, which is composed of an SIL-20A automatic sampler, two LC-20AD solvent delivery units, a CTO-20A column oven and an SPD-20A UV/VIS detector, and an LCMS2010EV single quadrupole mass spectrometer with an electrospray ionization (ESI) interface (Shimadzu). Aliquots $(10 \mu \mathrm{l})$ of standard or sample dissolved in $\mathrm{MeOH}$ were injected into the LC/MS system. The chromatographic separation was performed with a Shim-Pack VP-ODS column $(150 \times 4.6 \mathrm{~mm}$ [i.d.]; particle size, $5 \mu \mathrm{m}$; Shimadzu) maintained at $40^{\circ} \mathrm{C}$. $\mathrm{MeOH} / 100 \mathrm{mM}$ ammonium acetate was used as the mobile phase with the following gradient of acetonitrile: 0 to $5 \mathrm{~min}, 70 \%$; 5 to $26 \mathrm{~min}$, a linear gradient from $70 \%$ to $97 \%$; 26 to $28 \mathrm{~min}, 97 \%$; 28 to $30 \mathrm{~min}, 70 \%$. The flow rate of the mobile phase was $1.0 \mathrm{ml} / \mathrm{min}$. The mass spectrometer was operated in the selected ion monitoring mode with the following conditions: ionization mode, negative ion ESI; nebulizer gas, nitrogen; nebulizer gas flow, $1.5 \mathrm{~L} / \mathrm{min}$; prove voltage, $-3.5 \mathrm{kV}$; block heater temperature, $200{ }^{\circ} \mathrm{C}$; curved desolvation line temperature, $250^{\circ} \mathrm{C}$; monitoring ion, $\mathrm{m} / \mathrm{z} 313$.

\subsection{Statistical analysis}

Statistical analysis was conducted using the SPSS software (ver. 15.0 for Windows, SPSS Inc., Chicago, IL, USA). A Student's t-test was used to compare the agonistic activity of the samples before HPLC fractionation with that of the negative control. Differences were considered statistically significant at $p<0.05$.

\section{Results \\ 3.1. Seasonal variation in RAR $\alpha$ agonistic activity in Lake Biwa-Yodo River and Ina River}

To clarify the occurrence of RAR $\alpha$ agonists in the rivers, the RAR $\alpha$ agonistic activity was examined at stations $2,4,8$ and 18 of Lake Biwa-Yodo River and stations 5, 8, 11, 12, 17 and 18 of Ina River in four consecutive seasons from June 2007 to January 2008. In almost all cases in which significant activity was observed, the relative RAR $\alpha$ agonistic activity of a water sample increased in a dose-dependent fashion as the concentration factor increased from 0.1 to 100 .

The relative RAR $\alpha$ agonistic activity of the samples at a concentration factor of 100 is shown in Fig. 2 (see Table S1 for details including estimated atRA-EQ values). Significant RAR $\alpha$ agonistic activity $(p<0.05)$ was detected in all but two samples from station 18 in June 2007 and station 4 in October 2007 in Lake Biwa-Yodo River, and the relative activity at a concentration factor of 100 ranged from $2.0 \%$ to $52.7 \%$ and $1.5 \%$ to $24.2 \%$ in Lake Biwa-Yodo River and Ina River, respectively. Based on these results, the atRA-EQ of samples with significant RAR $\alpha$ agonistic activity was estimated to range from 0.6 to

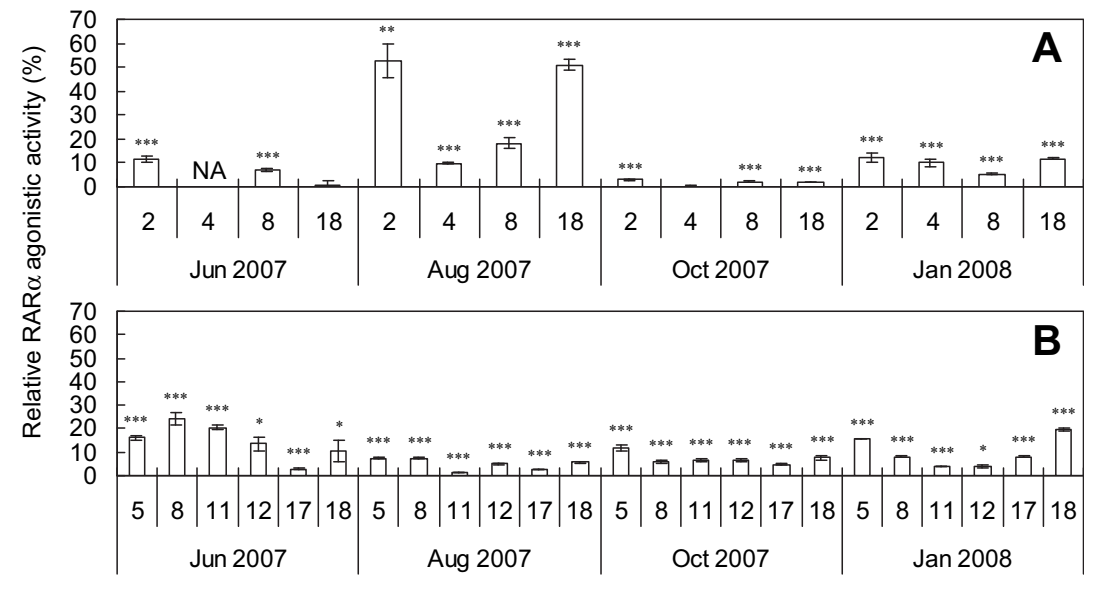

Fig. 2 - Temporal variation of relative RAR $\alpha$ agonistic activity at stations 2, 4, 8 and 18 of Lake Biwa-Yodo River (A) and stations 5, 8, 11, 12, 17 and 18 of Ina River (B). Results at a concentration factor of 100 in a yeast two-hybrid assay are presented. Maximal activity of atRA and activity of negative control are set at $100 \%$ and $0 \%$, respectively. Data shown are the means \pm SD $(n=3) .{ }^{*}, p<0.05 ;{ }^{* *}, p<0.01 ;{ }^{* * *}, p<0.005$ vs. the negative control. NA, not analyzed. 
47.6 ng-atRA/L and from 0.1 to $14.5 \mathrm{ng}$-atRA/L in Lake BiwaYodo River and Ina River, respectively (Table S1).

The relative RAR $\alpha$ agonistic activity of almost all the samples was less than $25 \%$ at a concentration factor of 100 (Fig. 2). Exceptionally, the samples collected at stations 2 and 18 in August 2007 in the Lake Biwa-Yodo River showed very high activities of $52.7 \%$ and $51.0 \%$ at a concentration factor of 100 , respectively. The estimated atRA-EQ values of these stations were 44.0 and $47.6 \mathrm{ng}$-atRA/L, respectively (Table S1). Additionally, in Ina River, the level of RAR $\alpha$ agonist contamination always increased between station 17 and station 18 (Fig. 2, Table S1).

\subsection{Spatial variation in RAR $\alpha$ agonistic activity along the rivers}

To determine the spatial variation of contamination with $\mathrm{RAR} \alpha$ agonists throughout the rivers, the RAR $\alpha$ agonistic activity was investigated at 20 stations in Ina River and 20 stations in Lake Biwa-Yodo River in April and October 2008, respectively. The ER $\alpha$ agonistic activity was also measured in the same 40 samples to compare the spatial distribution of the contamination with $\mathrm{ER} \alpha$ and $\mathrm{RAR} \alpha$ agonists.

In Ina River (April 2008), all 20 stations showed significant $\operatorname{RAR} \alpha$ agonistic activity $(p<0.01)$, with relative activities ranging from $2.4 \%$ to $26.6 \%$ at a concentration factor of 100 and estimated atRA-EQ values of 1.1 to $23.5 \mathrm{ng}$-atRA/L (Fig. 3A, Table S1). Contamination with the RAR $\alpha$ agonists was low and did not vary greatly in the upstream portion of the river, while the contamination levels varied greatly among stations in the midstream and downstream portions of the river. In the mainstream of the midstream and downstream portion of the river, the RAR $\alpha$ agonistic activity was high at stations $11,14,15$ and 18, while it was very low at stations 12, 17 and 20. Among these stations, stations 12, 17 and 18 are located downstream of municipal WWTPs, which indicates that the water quality at the stations is affected by the effluent from the WWTPs. A high level of RAR $\alpha$ agonists at station 18 and a low level at station 17 were also observed in the first investigations (Fig. 2).

In Lake Biwa-Yodo River (October 2008), significant RAR $\alpha$ agonistic activity $(p<0.01)$ was detected at all 20 stations, and the relative activity at a concentration factor of 100 and the estimated atRA-EQ ranged from $5.6 \%$ to $26.2 \%$ and 1.2 to $7.0 \mathrm{ng}$-atRA/L, respectively (Fig. 4A, Table. S1). Among the upstream stations, station 6 , which was primarily surrounded by residential and agricultural areas, showed a high activity. In addition, the contamination level at station 6 was approximately twice as large as the level observed at stations located upstream and downstream. In the midstream (between stations 7 and 14), where several WWTPs are distributed, the contamination level was generally low with small variations. By contrast, the RAR $\alpha$ agonistic activity appeared to be higher in the downstream portion of the river than in the upstream and midstream portions. The contamination level increased consistently between stations 16 and 18, where green space, including a golf course, is distributed along the river. The contamination level remained high at station 20.

Measurement of the ER $\alpha$ agonistic activity of the same 40 samples revealed significant $\mathrm{ER} \alpha$ agonistic activity $(p<0.05)$ at only 8 stations (stations 6 to 9 and 17 to 20) in the Ina River in April 2008 and at 3 stations (stations 7, 11 and 12) in the Lake Biwa-Yodo River in October 2008 (Figs. 3B and 4B). Stations 17 and 18 in the Ina River were located just downstream of a large WWTP and a small WWTP, respectively. Similarly, several WWTPs are distributed in the midstream portion of the Lake Biwa-Yodo River, which contains stations 7, 11 and 12. Thus, the sporadic occurrence of $\mathrm{ER} \alpha$ agonistic activity in the rivers would primarily be related to the discharge of effluents containing estrogenic compounds from the WWTPs, as suggested in previous studies (Sumpter, 1995; Vajda et al., 2008). Comparison of the occurrence of RAR $\alpha$ and ER $\alpha$ agonistic activities revealed that the spatial variation pattern of RAR $\alpha$ agonist contamination in the rivers investigated in this study was completely different from that of estrogenic compound contamination (Figs. 3 and 4).

\subsection{Characterization of RAR $\alpha$ agonists in the monitored rivers}

To characterize the RAR $\alpha$ agonists in the rivers monitored in this study, samples collected from several stations during different periods were fractionated by reverse-phase HPLC, and fractions were collected every $2 \mathrm{~min}$ from 0 to $44 \mathrm{~min}$ and then subjected to a yeast two-hybrid assay. Irrespective of the rivers, stations and seasons, the fraction collected between 24 and $26 \mathrm{~min}$ commonly showed a strong RAR $\alpha$ agonistic activity (Fig. 5A to C; see Supplementary Fig. S1 for all results). Therefore, the RAR $\alpha$ agonistic activity of the original samples without fractionation and the fraction eluted between 24 and 26 min from samples with a concentration factor of 100 were compared for nine samples (Fig. S1B to J). The fraction between 24 and $26 \mathrm{~min}$ represented nearly $50 \%$ to $160 \%$ of the RAR $\alpha$ agonistic activity of the original water samples in six of the nine samples (Fig. S1B, E to G, I, J). Additionally, this faction of samples collected from stations 5 and 18 of Ina River in August 2007 exhibited very high RAR $\alpha$ agonistic activities of $390 \%$ and $804 \%$, respectively, when compared with the original samples (Fig. S1C, D). Conversely, the RAR $\alpha$ agonistic activity of the 24 to 26 min fraction of the sample collected from station 5 of Ina River in January 2008 was only $4.7 \%$ when compared with that of the original sample (Fig. S1H). The very high activity of the 24 to $26 \mathrm{~min}$ fraction of the samples collected in August 2007 from stations 5 and 18 of Ina River may have been due to the efficient removal of interfering compounds that mask the RAR $\alpha$ agonistic activity by HPLC fractionation; however, the reason for the low activity of the sample collected from station 5 of Ina River in January 2008 is unclear. Nevertheless, these results indicated that the fraction between 24 and 26 min was primarily responsible for the RAR $\alpha$ agonistic activity observed in the water samples analyzed in this study. More detailed fractionation at 0.5-min intervals revealed that the highest RAR $\alpha$ agonistic activity was obtained in a fraction eluted between 25 and 25.5 min (Supplementary Fig. S2). In addition to the fraction between 24 and $26 \mathrm{~min}$, another fraction between 20 and $22 \mathrm{~min}$ also showed strong RAR $\alpha$ agonistic activity in several samples (Fig. 5C, Fig. S1D, G and $\mathrm{H}$ ). These results suggest that at least two RAR $\alpha$ agonists (major and minor contaminants) were present in the study area. 


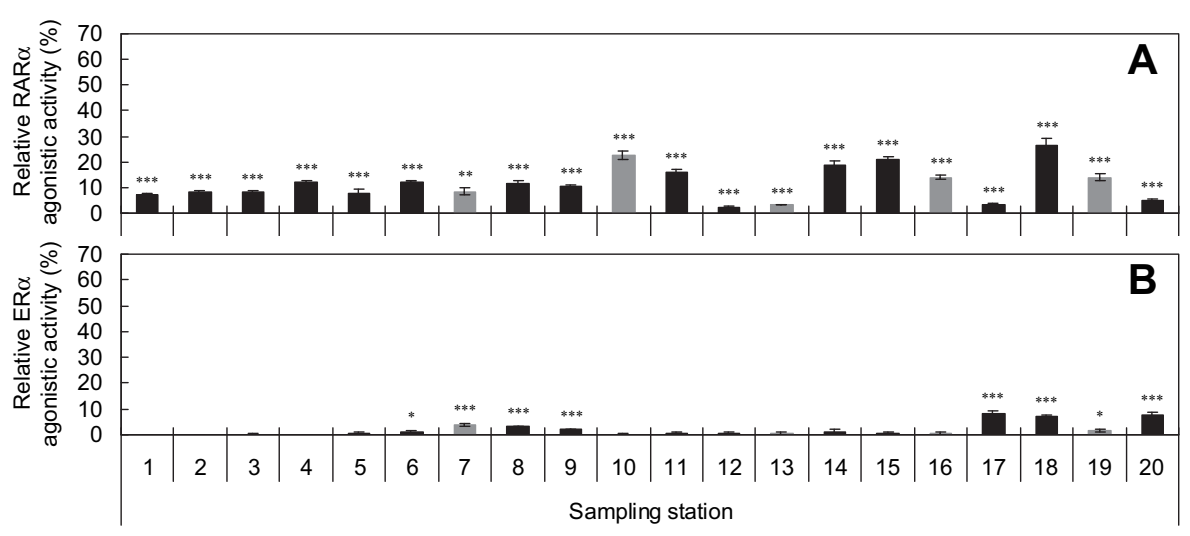

Fig. 3 - Agonistic activity against RAR $\alpha$ (A) and ER $\alpha$ (B) at 20 stations of Ina River in April 2008. Results at a concentration factor of $\mathbf{1 0 0}$ in a yeast two-hybrid assay are presented. Black and gray bars represent stations in the mainstream and tributaries, respectively. Maximal activity of positive chemical (atRA for RAR $\alpha$ or E2 for ER $\alpha$ ) and activity of negative control are set at $100 \%$ and $0 \%$, respectively. Data shown are the means $\pm \operatorname{SD}(n=3) .{ }^{*}, p<0.05 ;{ }^{* *}, p<0.01 ;{ }^{* * *}, p<0.005$ vs. the negative control.

To identify the causative compounds, compounds in the samples were monitored at a wavelength of $254 \mathrm{~nm}$ during reverse-phase HPLC fractionation. However, no significant peaks were detected at 24 to $26 \mathrm{~min}$, although several minute peaks were present. Thus, RAs (atRA, 9cRA and 13cRA) and 4-oxo-RAs (4-oxo-atRA, 4-oxo-9cRA and 4-oxo-13cRA) were also analyzed by reverse-phase HPLC under the same conditions at a different wavelength $(360 \mathrm{~nm})$. RAs were detected at RTs of 34.3 to $35.9 \mathrm{~min}$ and did not overlap with the RAR $\alpha$ agonistic fraction (Supplementary Fig. S3). 4-Oxo-atRA, 4-oxo9cRA and 4-oxo-13cRA were detected at RTs of 26.0, 26.8 and $26.6 \mathrm{~min}$, respectively (Fig. S3). In addition, 4-oxo-atRA and 4-oxo-13cRA were detected at RTs of 25.7 and $26.4 \mathrm{~min}$, respectively, when they were spiked into the river water sample (Fig. 5D). Because these compounds had RTs similar to that of the major RAR $\alpha$ agonistic fraction (24 to $26 \mathrm{~min}$ ), LC/MS analysis was performed to detect and quantify 4-oxo-atRA and 4-oxo-13cRA in the bioactive HPLC fraction between 24 and $26 \mathrm{~min}$ of a river water sample collected from station 18 of the Ina River in October 2009 (Table S1). The concentrations of 4-oxo-atRA and 4-oxo-13cRA in the sample were below the detection limit $(<0.01 \mathrm{ng} / \mathrm{L})$ and $0.20 \mathrm{ng} / \mathrm{L}$, respectively (Supplementary Fig. S4). On the other hand, yeast two-hybrid assays of 4-oxo-RAs revealed that the concentrations of 4-oxoatRA and 4-oxo-13cRA should be equivalent to or higher than $0.06 \mathrm{ng} / \mathrm{L}$ and $0.48 \mathrm{ng} / \mathrm{L}$, respectively, to exhibit a significant RAR $\alpha$ agonistic activity in the sample at a concentration factor of 100. Therefore, the contribution of 4-oxo-RAs to the RAR $\alpha$ agonistic activity detected in the samples analyzed here would be ignorable. These findings suggest that RAs and 4-oxo-RAs were not the causative RAR $\alpha$ agonists in the rivers investigated in this study, even though 4-oxo-RAs have been identified as major RAR agonists in sewage in Beijing, China (Zhen et al., 2009).

\section{Discussion}

This is the first study to investigate the spatial and seasonal variations in $R A R \alpha$ agonist contamination in entire rivers in Japan. The results obtained in this study clearly demonstrated that RAR $\alpha$ agonists occurred at a significant level in the rivers

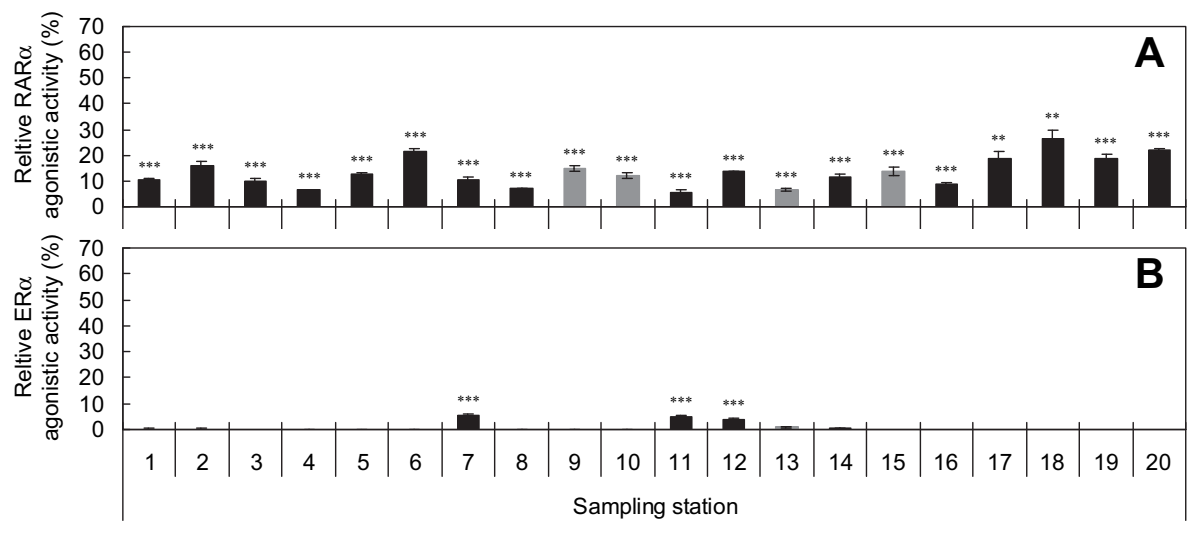

Fig. 4 - Agonistic activity against $\operatorname{RAR} \alpha(\mathrm{A})$ and $\mathrm{ER} \alpha(\mathrm{B})$ at 20 stations of Lake Biwa-Yodo River in October 2008. Results at a concentration factor of $\mathbf{1 0 0}$ in a yeast two-hybrid assay are presented. Black and gray bars represent stations in the mainstream and tributaries, respectively. Maximal activity of atRA and activity of negative control are set at $100 \%$ and $0 \%$, respectively. Data shown are the means $\pm \operatorname{SD}(n=3) .{ }^{* *}, p<0.01 ;{ }^{* * *}, p<0.005$ vs. the negative control. 


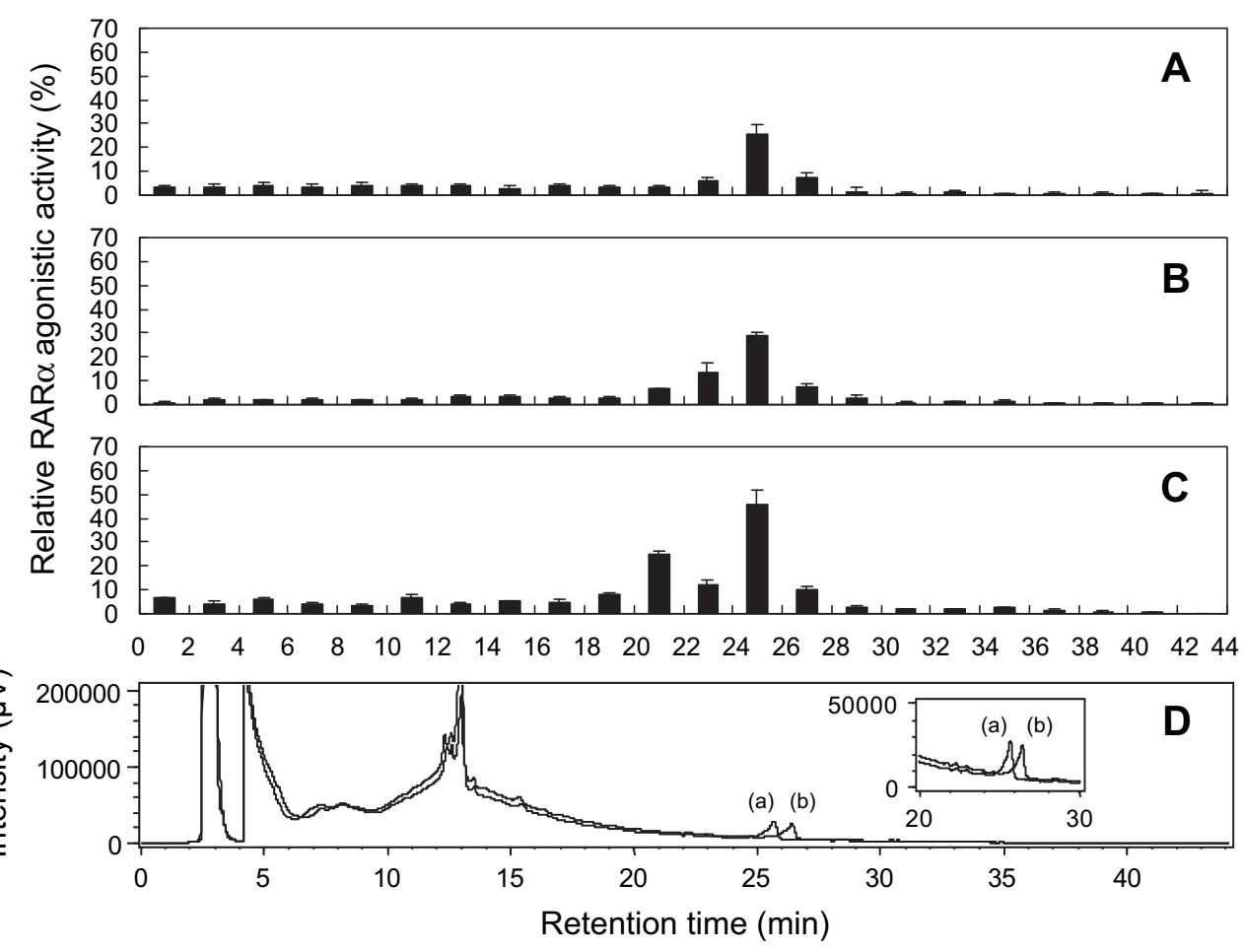

Fig. 5 - Typical RAR $\alpha$ agonistic activity of the HPLC fractions of river water samples (A to C). Results for samples collected from station 2 of Yodo River (A), and stations 5 (B) and 18 (C) of Ina River in August 2007 are presented. The concentration factors of samples in a yeast two-hybrid assay were 100. Maximal activity of atRA and activity of negative control are set at $100 \%$ and $0 \%$, respectively. Data shown are the means \pm SD $(n=3)$. Bottom panel $(D)$ shows the HPLC chromatograms of 4-oxo-atRA (a) and 4-oxo-13cRA (b) spiked into the extract of a river water sample. A sample collected from station 18 of Ina River in October 2009 was used and 4-oxo-RAs were spiked at a final concentration of $1.0 \mathrm{mg} / \mathrm{L}$. Detection was performed at a wavelength of $360 \mathrm{~nm}$.

monitored in this study, regardless of the season. The results also demonstrated that contamination with RAR $\alpha$ agonists was widely distributed throughout both rivers and that the contamination level appeared higher in the downstream portion of the rivers than the upstream portion. Contamination with RAR $\alpha$ agonists was detected not only in urban areas such as the midstream and downstream portions of the Lake Biwa-Yodo River, where a large amount of anthropogenic wastewater is discharged, but also in suburban areas with less human activity, such as the upstream portion of the Ina River.

In a previous investigation conducted in Beijing, China, the highest atRA-EQ level observed in river water samples was 11 ng-atRA/L (Zhen et al., 2009). On the other hand, the highest atRA-EQ of the samples analyzed here was $47.6 \mathrm{ng}$-atRA/L, and several samples had atRA-EQ values of greater than $10 \mathrm{ng}$ atRA/L (Table S1). Thus, contamination with RAR $\alpha$ agonists was greater in the Kinki region of Japan than in Beijing, China.

The spatial distribution profile of the RAR $\alpha$ agonist contamination in the rivers investigated in this study was completely different from that of the estrogenic contamination (Figs. 3 and 4). Specifically, the level of RAR $\alpha$ agonist contamination was lower at most of the stations located downstream of WWTPs, which are well-known sources of estrogenic contaminants. Evaluation of RAR $\alpha$ agonistic activity in several WWTPs in Japan, including those located along the rivers investigated in this study, revealed that the
RAR $\alpha$ agonistic activity of their effluent was not high enough to increase the activity of the receiving rivers (data not shown). In addition, in Ina River, although the level of RAR $\alpha$ agonist contamination at station 18 , which is located downstream of a small WWTP, was always higher than station 17 (Figs. 2 and $3 \mathrm{~A}$ ), measurement of RAR $\alpha$ agonistic activity at stations 17 and 18 and the WWTP on the same day found that the activity of WWTP effluent was lower than those of surface water samples at stations 17 and 18 (data not shown). Therefore, WWTPs would not be a major source of RAR $\alpha$ agonist contamination in the rivers investigated in this study. Instead, WWTP effluents that contained small amounts of RAR $\alpha$ agonists may have reduced the contamination level in the receiving rivers via a dilution effect.

It was confirmed that at least two distinct RAR $\alpha$ agonists were present in the surface water samples investigated in this study. However, they were not 4-oxo-RAs, which have been first identified as the major causative compounds of RAR agonistic activity in sewage in Beijing (Zhen et al., 2009), suggesting that the causative compounds of RAR $\alpha$ agonistic activity in river water would not stem from the sewage discharging, but from other sources which should be further studied. However, results in this study do not completely exclude the possibility that 4-oxo-RAs are present in the rivers. That is, because SPE procedures applied in this study were different from those reported in the previous study 
Table 1 - Comparison of the maximal atRA-EQ levels observed in Lake Biwa-Yodo River and Ina River with the minimal concentrations of atRA that induce teratogenesis in various animals.

\begin{tabular}{|c|c|c|c|}
\hline Animal species & $\begin{array}{l}\text { atRA-EQ or minimal } \\
\quad \text { effective atRA } \\
\text { concentration }(\mathrm{ng} / \mathrm{L})\end{array}$ & Observed malformations & References \\
\hline & 47.6 & & $\begin{array}{l}\text { This study } \\
\text { (Lake Biwa-Yodo River) }\end{array}$ \\
\hline & 23.5 & & This study (Ina River) \\
\hline $\begin{array}{l}\text { Brachydanio rerio } \\
\text { (zebrafish) }\end{array}$ & 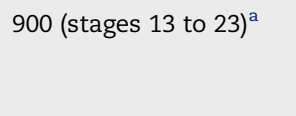 & $\begin{array}{l}\text { Edema in yolk sac and heart; Brain deformity } \\
\text { (microcephaly); Tail deformity } \\
\text { (shortened and bent tail) }\end{array}$ & Herrmann, 1995 \\
\hline $\begin{array}{l}\text { Paralichthys olivaceus } \\
\text { (Japanese flounder) }\end{array}$ & $\begin{array}{l}7500 \text { ( } 6 \text { to } 9 \text { days } \\
\text { post hatching) }\end{array}$ & $\begin{array}{l}\text { Lower jaw deformity (growth retardation of dentary); } \\
\text { Caudal fin deformity (partial or complete loss of caudal fin); } \\
\text { Vertebral deformity (central fusion, hypertrophy of centrum } \\
\text { and additional abdominal vertebrae) }\end{array}$ & Haga et al., 2002 \\
\hline Xenopus laevis & 600 (stages 8 to 41 ) & $\begin{array}{l}\text { Craniofacial defect (micropthalmia, reductions in } \\
\text { prosencephalon and mesencephalon and edema) }\end{array}$ & Degitz et al., 2003 \\
\hline Sprague-Dawley rat & $\begin{array}{l}10,000 \\
\text { ( } 46 \mathrm{~h} \text { from } 9 \text { days } \\
\text { post coitum) }\end{array}$ & Malformation of second visceral arch & Ritchie et al., 2003 \\
\hline
\end{tabular}

a Parentheses show the exposure periods.

(Zhen et al., 2009), 4-oxo-RAs might not be sufficiently recovered from the surface water samples in this study.

Recent studies have also reported that synthetic compounds such as organochlorine pesticides, styrene dimers, monoalkylphenols and parabens show RAR agonistic activity in vitro (Nishikawa et al., 2003; Lemaire et al., 2005; Kamata et al., 2008). However, due to their low potencies, any contribution to the RAR $\alpha$ agonistic activity of our samples should be negligible at normal environmental concentrations. Therefore, it is suggested that entirely-new unknown RAR $\alpha$ agonists were present in the rivers investigated in this study, but it is not known if the causative contaminants were naturally-occurring compounds such as RA metabolites other than 4-oxo-RAs, or unknown RAR $\alpha$ agonistic xenobiotic compounds.

Although the causative contaminants were not identified, the elevated contamination levels observed at some stations (Figs. 3A and 4A) suggested the presence of several sources of RAR $\alpha$ agonists along the rivers. Considering the land utilization patterns, industrial and agricultural effluents may be possible sources. Deformed frogs in North America that are believed to be caused by RAR agonists have been observed in agricultural areas (Gardiner et al., 2003). Thus, agricultural effluents may have impacted the RAR $\alpha$ agonist contamination levels in the rivers investigated in the present study. However, identification of the novel RAR $\alpha$ agonists is required to specify their source and elucidate their contamination in the aquatic environment.

Because the causative compounds were not identified, the potential biological risk of the RAR $\alpha$ agonists in the rivers was assessed, instead, based on the atRA-EQ values estimated from the results of the yeast assay. Among 35 samples collected from the Lake Biwa-Yodo River, the maximum atRAEQ of $47.6 \mathrm{ng}$-atRA/L was obtained from a sample collected at station 18 in August 2007 (Table S1). Among 46 samples collected from the Ina River, the maximum atRA-EQ of $23.5 \mathrm{ng}$-atRA/L was observed in a sample collected from station 18 in April 2008 (Table S1). Although the effective dose of atRA differs depending on the species and exposure timing and duration, it has been reported that chronic exposure of atRA at hundreds of $\mathrm{ng} / \mathrm{L}$ or more can cause teratogenesis in fish, amphibians and mammals (Table 1). Degitz et al. (2003) reported that chronic exposure to atRA at a concentration of $600 \mathrm{ng} / \mathrm{L}$ for $3 \mathrm{~d}$ caused a wide spectrum of malformations in Xenopus laevis embryos. The maximum atRA-EQ values detected in Lake Biwa-Yodo River and Ina River were 13- and 26-fold lower than this minimal effective atRA concentration, respectively (Table 1). Therefore, the level of RAR $\alpha$ agonists observed in the rivers investigated in this study is not likely to cause RAR-mediated deleterious biological effects at present. However, this does not mean that RAR-mediated adverse effects in response to RAR $\alpha$ agonists never occur. A marked temporal/spatial increase in the contamination level as observed in the Lake Biwa-Yodo River during summer (Fig. 2) may unexpectedly cause RAR-mediated adverse effects. Furthermore, it has been reported that xenoestrogens such as nonylphenol and bisphenol A exhibit greater estrogenic potency in vivo than in vitro (Strunck et al., 2000; Folmar et al., 2002). The possibility that similar phenomenon might occur for the RAR $\alpha$ agonists targeted in this study cannot be ruled out, if they are not naturally-occurring compounds but xenobiotic compounds. Thus, the identification of causative compounds is essential to accurately assess the potential endocrine disruptive effects of RAR $\alpha$ agonists present in the natural aquatic environment.

\section{Conclusion}

To elucidate RAR $\alpha$ agonist contamination in the aquatic environment in the Kinki region of Japan, the RAR $\alpha$ agonistic activity in Lake Biwa-Yodo River and Ina River was investigated in detail using a yeast two-hybrid assay. The following conclusions were drawn from the results of this study: 
- RAR $\alpha$ agonist contamination was always present and widespread in the rivers investigated in this study.

- The spatial variation pattern of RAR $\alpha$ agonist contamination was completely different from that of ER $\alpha$ agonist contamination, and effluent from WWTPs appeared not to be a major source of RAR $\alpha$ agonists.

- There appears to be at least two distinct RAR $\alpha$ agonists, which were not RAs (natural RAR ligands) and 4-oxo-RAs (the causative RAR $\alpha$ agonists identified in sewage in Beijing, China) but entirely unknown compounds.

- The current contamination level of RAR $\alpha$ agonists in the aquatic environment do not appear to be high enough to exert RAR-mediated deleterious effects on wild animals.

To better understand the contamination of the aquatic environment by $\mathrm{RAR} \alpha$ agonists and assess their possible ecological risks in detail, the causative contaminants should be identified, and their occurrence and fate in the aquatic environment should be fully characterized.

\section{Acknowledgements}

This study was supported in part by the FY2008 Environmental Technology Development Fund of the Ministry of the Environment, Japan, and the Grant-in-Aid for Young Scientists (B) 20760362 from the Ministry of Education, Culture, Sports, Science and Technology, Japan.

\section{Appendix A. Supplementary information}

Supplementary material associated with this article can be found in the online version at doi:10.1016/j.watres.2010.01.005.

\section{R E F E R E N C E S}

Alsop, D.H., Brown, S.B., van der Kraak, G.J., 2004. Dietary retinoic acid induces hindlimb and eye deformities in Xenopus laevis. Environ. Sci. Technol. 38, 6290-6299.

Campbell, C.G., Borglin, S.E., Green, F.B., Grayson, A., Wozei, E., Stringfellow, W.T., 2006. Biologically directed environmental monitoring, fate, and transport of estrogenic endocrine disrupting compounds in water: a review. Chemosphere 65, 1265-1280.

Chambon, P., 1996. A decade of molecular biology of retinoic acid receptors. FASEB J. 10, 940-954.

Chawla, A., Repa, J.J., Evans, R.M., Mangelsdorf, D.J., 2001. Nuclear receptors and lipid physiology: opening the X-files. Science 294, 1866-1870.

Collins, M.D., Mao, G.E., 1999. Teratology of retinoids. Annu. Rev. Pharmacol. Toxicol. 39, 399-430.

Degitz, S.J., Kosian, P.A., Makynen, E.A., Jensen, K.M., Ankley, G.T., 2000. Stage- and species-specific developmental toxicity of all-trans retinoic acid in four native North American ranids and Xenopus laevis. Toxicol. Sci. 57, 264-274.

Degitz, S.J., Holcombe, G.W., Kosian, P.A., Tietge, J.E., Durhan, E.J., Ankley, G.T., 2003. Comparing the effects of stage and duration of retinoic acid exposure on amphibian limb development: chronic exposure results in mortality, not limb malformations. Toxicol. Sci. 74, 139-146.
Folmar, L.C., Hemmer, M.J., Denslow, N.D., Kroll, K., Chen, J., Cheek, A., Richman, H., Meredith, H., Grau, E.G., 2002. A comparison of the estrogenic potencies of estradiol, ethynylestradiol, diethylstilbestrol, nonylphenol and methoxychlor in vivo and in vitro. Aquat. Toxicol. 60, 101-110.

Gardiner, D., Ndayibagira, A., Grün, F., Blumberg, B., 2003. Deformed frogs and environmental retinoids. Pure Appl. Chem. 75, 2263-2273.

Haga, Y., Suzuki, T., Takeuchi, T., 2002. Retinoic acid isomers produce malformations in postembryonic development of the Japanese flounder, Paralichthys olivaceus. Zoolog. Sci. 19, 1105-1112.

Herrmann, K., 1995. Teratogenic effects of retinoic acid and related substances on the early development of the zebrafish (Brachydanio rerio) as assessed by novel scoring system. Toxicol. In Vitro 9, 267-283.

Inoue, D., Nakama, K., Matsui, H., Sei, K., Ike, M., 2009. Detection of agonistic activities against five human nuclear receptors in river environments of Japan using a yeast two-hybrid assay. Bull. Environ. Contam. Toxicol. 82, 399-404.

Janošek, J., Hilscherová, K., Bláha, L., Holoubek, I., 2006. Environmental xenobiotics and nuclear receptors-Interactions, effects and in vitro assessment. Toxicol. In Vitro 20, 18-37.

Kamata, R., Shiraishi, F., Nishikawa, J., Yonemoto, J., Shiraishi, H., 2008. Screening and detection of the in vitro agonistic activity of xenobiotics on the retinoic acid receptor. Toxicol. In Vitro 22, 1050-1061.

Kastner, P., Mark, M., Chambon, P., 1995. Nonsteroid nuclear receptors: what are genetic studies telling us about their role in real life? Cell 83, 859-869.

Kawagoshi, Y., Fujita, Y., Kishi, I., Fukunaga, I., 2003. Estrogenic chemicals and estrogenic activity in leachate from municipal waste landfill determined by yeast two-hybrid assay. J. Environ. Monit. 5, 269-274.

Lee, Y.M., Osumi-Yamashita, N., Ninomiya, Y., Moon, C.K., Eriksson, U., Eto, K., 1995. Retinoic acid stage-dependently alters the migration pattern and identity of hindbrain neural crest cells. Development 121, 825-837.

Lemaire, G., Balaguer, P., Michel, S., Rahmani, R., 2005. Activation of retinoic acid receptor-dependent transcription by organochlorine pesticides. Toxicol. Appl. Pharmacol. 202, 38-49.

Nishikawa, J., Saito, K., Goto, J., Dakeyama, F., Matsuo, M., Nishihara, T., 1999. New screening methods for chemicals with hormonal activities using interaction of nuclear hormone receptor with coactivator. Toxicol. Appl. Pharmacol. 154, 76-83.

Nishikawa, J., Mamiya, S., Kanayama, T., Nishihara, T., 2003. Effect of suspected endocrine disruptors on various kinds of nuclear hormone receptors. J. Environ. Biotechnol. 3, 37-42 (in Japanese).

Ritchie, H.E., Brown-Woodman, P.D., Korabelnikoff, A., 2003. Effect of co-administration of retinoids on rat embryo development in vitro. Birth Defects Res. A Clin. Mol. Teratol. 67, 444-451.

Rothman, K.J., Moore, L.L., Singer, M.R., Nguyen, U.S., Mannino, S., Milunsky, A., 1995. Teratogenicity of high vitamin A intake. N. Engl. J. Med. 333, 1369-1373.

Sharma, V.K., Anquandah, G.A., Yngard, R.A., Kim, H., Fekete, J., Bouzek, K., Ray, A.K., Golovko, D., 2009. Nonylphenol, octylphenol, and bisphenol-A in the aquatic environment: a review on occurrence, fate, and treatment. J. Environ. Sci. Health A 44, 423-442.

Sporn, M., Roberts, A., Goodman, D., 1994. The Retinoids: Biology, Chemistry, and Medicine. Raven Press, New York.

Strunck, E., Stemmann, N., Hopert, A.C., Wünsche, W., Frank, K., Vollmer, G., 2000. Relative binding affinity does not predict 
biological response to xenoestrogens in rat endometrial adenocarcinoma cells. J. Steroid Biochem. Mol. Biol. 74, 73-81.

Sumpter, J.P., 1995. Ferminized responses in fish to environmental estrogens. Toxicol. Lett. 82-83, 737-742.

Tabb, M.M., Blumberg, B., 2006. New modes of action for endocrine-disrupting chemicals. Mol. Endocrinol. 20, 475-482.

Vajda, A.M., Barber, L.B., Gray, J.L., Lopez, E.M., Woodling, J.D., Norris, D.O., 2008. Reproductive disruption in fish downstream from an estrogenic wastewater effluent. Environ. Sci. Technol. 42, 3407-3414.

Zhen, H., Wu, X., Hu, J., Xiao, Y., Yang, M., Hirotsuji, J., Nakanishi, T., Nishikawa, J., Ike, M., 2009. Identification of retinoic acid receptor agonists in sewage treatment plants. Environ. Sci. Technol. 43, 6611-6616.

Zile, M.H., 2001. Function of vitamin A in vertebrate embryonic development. J. Nutr. 131, 705-708. 